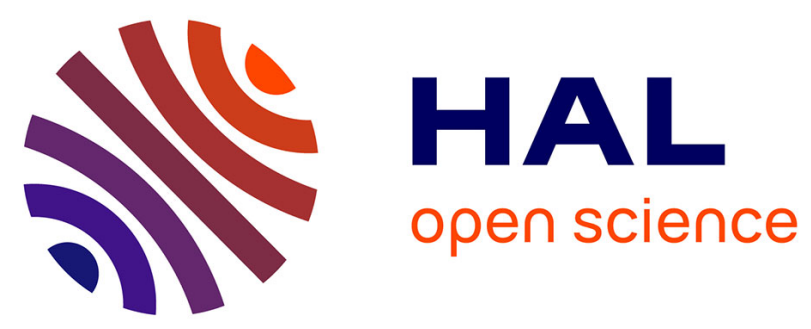

\title{
Enhanced expression and activation of pro-inflammatory transcription factors distinguish aneurismal from atherosclerotic aorta: IL-6 and IL-8 dominated inflammatory responses prevail in the human aneurysm
} Jan Hn Lindeman, Hazem Abdul-Hussien, Alexander Fm Schaapherder, J. Hajo van Bockel, Jan H von Der Thüsen, Dave L Roelen, Robert Kleemann

\section{To cite this version:}

Jan Hn Lindeman, Hazem Abdul-Hussien, Alexander Fm Schaapherder, J. Hajo van Bockel, Jan H von Der Thüsen, et al.. Enhanced expression and activation of pro-inflammatory transcription factors distinguish aneurismal from atherosclerotic aorta: IL-6 and IL-8 dominated inflammatory responses prevail in the human aneurysm. Clinical Science, 2007, 114 (11), pp.687-697. 10.1042/CS20070352 . hal-00479405

\section{HAL Id: hal-00479405 https://hal.science/hal-00479405}

Submitted on 30 Apr 2010

HAL is a multi-disciplinary open access archive for the deposit and dissemination of scientific research documents, whether they are published or not. The documents may come from teaching and research institutions in France or abroad, or from public or private research centers.
L'archive ouverte pluridisciplinaire HAL, est destinée au dépôt et à la diffusion de documents scientifiques de niveau recherche, publiés ou non, émanant des établissements d'enseignement et de recherche français ou étrangers, des laboratoires publics ou privés. 


\section{Enhanced expression and activation of pro-inflammatory transcription factors distinguish aneurismal from atherosclerotic aorta: \\ IL-6 and IL-8 dominated inflammatory responses prevail in the human aneurysm}

Jan H.N. Lindeman, ${ }^{1)}$ Hazem Abdul-Hussien, ${ }^{1)}$ Alexander F.M. Schaapherder, ${ }^{1)}$ J. Hajo van Bockel, ${ }^{1)}$ Jan von der Thüsen, ${ }^{2)}$ Dave L. Roelen, ${ }^{3)}$ Robert Kleemann ${ }^{4}$

Departments of ${ }^{1)}$ Vascular and Transplantation Surgery, ${ }^{2}$ Pathology, and

${ }^{3)}$ Immunohematology and Blood Transfusion, Leiden University Medical Center, and

4)TNO-Quality of Life, Dept. of Vascular and Metabolic Diseases, Leiden, The Netherlands

Corresponding author:

Jan H.N. Lindeman, MD, PhD

Dept Vascular Surgery, K6R

Leiden University Medical Center

PO Box 9600

2300 RC Leiden, The Netherlands

$0031715263968(\mathrm{~T}), 0031715266750(\mathrm{~F})$

Email: Lindeman@LUMC.nl

Revised version, number of text pages: 23; tables: 5; figures: 4 .

Supported by The Netherlands Heart Foundation (NHS 2000B165)

Conflicts of interest: none 


\section{Abstract}

Inflammation plays a key-role in the pathogenesis of the abdominal aortic aneurysm (AAA). Yet, the nature of the inflammatory factors and cellular response(s) involved in AAA growth is discussed controversially. Here, we set out to determine the aortic levels of inflammatory cytokines in relation to downstream inflammatory transcription factors and cellular responses. A comparison of AAA wall biopsies with atherosclerotic wall biopsies taken from the same aortic region allowed us to identify AAA-specific inflammatory parameters that distinguish AAA from aortic atheroscierotic disease (ASD).

RT-PCR, ELISA, Western blotting and immunohistochemistry were combined to assess cytokines and transcription factors on the mRNA and protein level, and their activation status. Compared to ASD, inflammatory parameters associated with Th1-

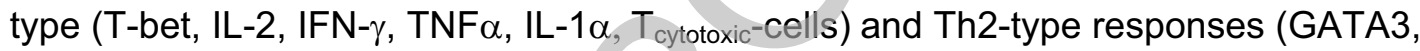
IL-4, IL-10, IL-13, B-cells) were all elevated in AAA. Evaluation of major downstream inflammatory transcription factors revealed higher baseline levels of $\mathrm{C} / \mathrm{EBP} \alpha, \beta$ and $\delta$ in AAA. Baseline p65-NF-кB and c-jun (AP-1) levels were comparable, but their activated forms were strongly increased in AAA. Downstream target genes of p65-NF$\mathrm{B}$ and c-jun, IL-6 and IL-8, were hyperexpressed. Molecular and cellular processes associated with IL-6 and IL-8 hyperactivation were enhanced in AAA, i.e. the expression of p-STAT-3 and perforin was elevated, and the content of plasma cells, neutrophils and vasa vasorum was increased.

Our findings demonstrate that AAA is a general inflammatory condition that is characterized by enhanced expression and activation of pro-inflammatory transcription factors, accompanied by IL-6 and IL-8 hyperexpression and exaggerated downstream cellular responses, together clearly distinguishing AAA from ASD. 


\section{Introduction}

An abdominal aortic aneurysm (AAA) is a focal balloon-like dilatation of the terminal aortic segment. The atherosclerotic aneurysm, the common fusiform form of AAA is a frequent pathology and a major cause of death due to rupture. [1] The hallmark pathology of atherosclerotic AAA is a chronic inflammatory condition of the arterial wall that is accompanied by a proteolytic imbalance. [2] Increased proteolytic activity results in excessive matrix degradation and progressive weakening of the vessel wall. [3] Despite considerable knowledge of the pathomorphology of AAA, understanding of the cellular and molecular inflammatory processes which underlie the increased protease expression and that drive aneurysmal growth is limited.[3] Available human studies analyzing the cellular composition of AAA indicate an extensive, heterogeneous inflammatory response that involves macrophages, neutrophils, cytotoxic T-cells as well as T-helper 1 (Th1) and Th2 cell subsets. $[4,5,6]$

It is well established that the Th1/Th2-type balance is controlled tightly, and that exaggerated Th1 or Th2 responses are causatively associated with development of inflammatory pathologies. [7,8] Th1-and Th2-type cellular responses involve distinct (and partly even opposite) immune and inflammatory processes which are mediated by specific sets of cytokines and transcription factors. Whereas Th1-type responses are typically associated with enhanced expression of the cytokines IL-2 and IFN $\gamma$ and the transcription factor T-bet; Th2-type responses are characterized by dominance of IL-4, IL-5 and/or IL-10, and elevated levels of the transcriptional regulator GATA3. [9]

In the context of developing AAA, the Th1/Th2 balance is thought to play an important regulatory role in the control of matrix remodelling and inflammatory processes relevant for AAA growth and rupture. [3] However, the nature of the predominant cellular response (Th1 or Th2), and the inflammatory factors 


\section{Lindeman et al.}

predominantly involved in human AAA growth are discussed controversially. For example, Galle and coworkers reported a predominance of Th1-type cellular and cytokine responses [10] while other studies demonstrate predominance of a Th2-type immune response [11] which is reflected by an enhanced expression of Th2associated cytokines and minimal expression of the Th1-associated cytokine IFN $\gamma$ $[3,11]$ A recent protein array study assessing the cytokine and chemokine profile of aortic wall tissue from advanced $(>5.5 \mathrm{~cm})$ AAA reports upregulation of both Th1associated (IL-1, TNF $\alpha$ ) and Th2-associated (IL-10) inflammatory mediators. [12] The downstream consequences of these and similar $[13,14]$ observations remain uncertain since, on the level of transcription factors, the cytokines can exert opposite effects. For example, IL-1 can activate NF-kB while IL-10 can suppress its activation. With a comprehensive analysis of transcription factors lacking in the human studies performed so far, it remains unclear whether, and if so how, the observed changes in cytokine expression in human AAA wall affect the basal expression of major inflammatory transcription factors and their degree of activation.

In the present study, we set out to address this issue and characterized AAA samples $>5.5 \mathrm{~cm}$ with respect to their cytokine expression profile (on mRNA and protein level) and their cellular composition (using immunohistochemistry). We subsequently analyzed the basal expression levels of major inflammatory transcription factors (p65-NF-кB; c-jun; C/EBP $\alpha / \beta / \delta$, STAT3) and their activation status (active p65NF-kB; $p-c-j u n, p-S T A T 3$ ) in relation to relevant inflammatory processes controlled by these transcription factors, i.e. the expression of putative target genes (IL-6 and IL-8) and therewith associated cellular effects (B cell, plasma cell and neutrophil content; perforin expression). 


\section{Lindeman et al.}

Because a putatively exaggerated Th2 response in AAA would clearly distinguish this pathology from aortic atherosclerotic disease (ASD), which is governed by Th1-type cellular and cytokine responses [3], a comparison of AAA to ASD was thought to be relevant. The more so, since AAA and ASD share common pathologic features and risk factors, but differences in their pathogenesis are so far only poorly defined. [3]

Results of this analysis demonstrate elevated levels of the three C/EBP isoforms $(\alpha, \beta, \delta)$, and comparable basal but enhanced activated levels of the inflammatory transcription factors NF-kB and c-jun in AAA wall. These findings on the transcription factor level are in accordance with hyperexpression of downstream genes, in particular the cytokines IL-6 and IL-8, and subsequent functional effects on the molecular (increased p-STAT3) and cellular level (increased plasma cell and $\mathrm{T}_{\text {cytotoxic }}$ cell content). Altogether, these differences characterize AAA as an inflammatory condition and clearly distinguish AAA from ASD. 


\section{Materials and methods}

\section{Patients}

All human arterial wall samples were provided by the Vascular Tissue Bank (Department of Vascular Surgery, Leiden, The Netherlands). Sample collection and handling was performed in accordance with the guidelines of Medical Ethical Committee of the Leiden University Medical Center, Leiden, The Netherlands. All samples were obtained following patients' consent. None of the patients in the study had a history of diabetic or chronic inflammatory disease. Primary cause of the fatal brain injury in the ASD group was a major head trauma or subarachnoidal bleeding.

Anterior-lateral aneurysm wall samples were obtained from patients with AAA $>5.5 \mathrm{~cm}$ undergoing elective open repair (AAA group; $n=17 ; 72.4 \pm 6.2$ (mean $\pm \mathrm{sd}$ ) years; 14 males $/ 3$ females; AAA diameter: $6.7 \pm 1.1 \mathrm{~cm}$, Table 1). Due to reticent statin use only one AAA patient used a statin. For comparison of AAA wall with atherosclerotic aortic wall, we used non-aneurysmal aortic wall samples from braindead kidney donors. Only patches displaying advanced atherosclerotic with advanced atherosclerotic lesions (equalling the characteristics of grade IV-VI lesions (Stary classification [15])) were selected (ASD group; $n=11 ; 55.6 \pm 10.2$ years; 7 males/4 females; $<2.0 \mathrm{~cm}$ aortic diameter). Of note, all ASD samples were obtained from the level of the renal artery and during a laparotomy, i.e. from a comparable region and during a similar procedure as the AAA samples.

Adhering thrombus was carefully removed and the aortic walls (either AAA or ASD) were halved. One half was immediately snap-frozen (liquid nitrogen) and stored at $-80^{\circ} \mathrm{C}$ for mRNA (RT-PCR) and protein (Western blot, Multiplex and ELISA) 


\section{Lindeman et al.}

analysis. The other half was fixed in formaldehyde $(24 \mathrm{~h})$, decalcified (Kristensens solution, $120 \mathrm{~h}$ ) and embedded in paraffin for histological analysis.

$R N A$ extraction and $m R N A$ analysis

Total RNA extraction was performed using RNAzol (Campro Scientific, Veenendaal, The Netherlands) and glass beads according to the manufacturer's instructions. Then, cDNA was prepared using kit \#A3500 (Promega, Leiden, The Netherlands) for real-time polymerase chain reaction (RT-PCR) analysis. The mastermix (Eurogentec, Seraing, Belgium), an ABI-7700 system (Applied Biosytems, Nieuwekerk a/d IJssel, the Netherlands) and established primer/probe sets (Applied Biosystems, Table 2) were used according to the manufacturer's instructions and as reported. [16] Glyceraldehyde-3-phosphate dehydrogenase (GAPDH) was used as a reference and for normalization.

\section{Tissue homogenization for protein analysis}

Aortic wall tissues were pulverized in liquid nitrogen and homogenized in 2 volumes lysis buffer (10 mM Tris pH 7.0, $0.1 \mathrm{mM} \mathrm{CaCl}_{2}, 0.1 \mathrm{M} \mathrm{NaCl}, 0.25 \%(\mathrm{v} / \mathrm{v})$ Triton $\mathrm{X}-100)$. This protocol releases both soluble as well as membrane bound proteins. Samples were subsequently centrifuged at $10000 \mathrm{~g}$ for 15 minutes at $4^{\circ} \mathrm{C}$, snap-frozen in liquid nitrogen and stored at $-80^{\circ} \mathrm{C}$ until use. Protein content in homogenates was determined with a BCA protein assay kit (Pierce, Rockford, IL, USA).

\section{Multiplex assay and ELISAs.}

IL-1, IL-2, IL-4, IL-5, IL-6, IL-7, IL-8, IL-10, IL-12, IL-13, IL-17A, G-CSF, GMCSF, IFN- $\gamma$, MCP-1, MIP-1 $\beta$ and TNF $\alpha$ protein levels in tissue homogenates were 


\section{Lindeman et al.}

determined using a Bio-plex 17 panel for multiple cytokines (Bio-Rad Laboratories B.V, Veenendaal, the Netherlands). Detection thresholds for the above cytokines panel were $<0.5$ pg/ml (IL-1, IL-2, IL-5, IL-6, IL-7, IL- IL-8, IL-10, TNFa), <1 pg/mL (IL12, IL-17A), and < $5 \mathrm{pg} / \mathrm{mL}$ (IL-4, IL-13, G-CSF, GM-CSF, IFN- $\gamma$, MCP-1). IL-6, IL-8, and MCP-1 levels exceeded the upper detection limit of the Bio-plex 17 panel and were therefore determined accurately using separate specific ELISAs, i.e. PeliKane compact kit (CLB, Amsterdam, The Netherlands) for IL-6 and IL-8 and Quantikine kit (R\&D Systems, Abingdon, UK) for MCP-1. Soluble IL-6 receptor levels were determined using an ELISA specific for human IL-6sR (R\&D Systems).

\section{Western blot analysis}

Western blot analyses was performed essentially as described[17] using

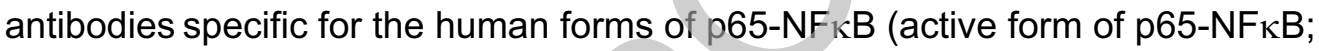
Chemicon, \#MAB3026, Chemicon Europe, Ltd., Chandlers Ford, UK); p65-NFkB (nonactive form; sc-8008; Santa Cruz, Heerhugowaard, The Netherlands); c-Jun (sc-45), phospho(Ser73)-c-Jun (sc-7981), perforin (sc-7417), STAT3 (sc-7179) phosphoSTAT3 (Epitomics PS727), Huissen, The Netherlands), C/EBP $\alpha$ (sc-9315), C/EBP $\beta$ (sc-150), C/EBP $\delta$ (sc-636) and $\beta$-actin sc-1615 as established. [18]

Corresponding secondary antibodies were obtained from Santa Cruz Biotechnology (donkey anti-goat) and Pierce (Etten-Leur, The Netherlands; goat antirabbit and goat anti-mouse). Immunoblots were visualized and quantified using the Super Signal West Dura Extended Duration Substrate (Perbio Science, Etten-Leur, The Netheriands), LabWorks 4.6 software and a luminescent image workstation (UVP, Cambridge, UK). Protein expression levels in aortic wall samples were normalized for $\beta$-actin, and separate anti- $\beta$-actin immunoblots were performed for each sample. 


\section{Immunohistochemistry}

Immunohistochemistry was performed using deparaffinized, ethanol dehydrated tissue cross-sections (thickness: $4 \mu \mathrm{m}$ ) essentially as described. [16,19] Crosssections were incubated overnight with polyclonal antibodies specifically staining human Myeloperoxidase (1:4000 dilution, DAKO, Heverlee, Belgium), CD20 (1:1000 dilution, DAKO, Heverlee, Belgium), CD138 (1:1000 dilution, Serotec, Oxford, UK), IL6 or IL-8 (1:2000 and 1:200 dilution respectively, both from Biogenesis, Ede, The Netherlands). Conjugated biotinylated anti-goat or rabbit anti-lgG were used as secondary antibodies. Sections were developed with Nova Red ${ }^{\circledR}$ (Vector Laboratories, Burlingame, CA) and counterstained with Mayer Hematoxylin allowing morphological analysis. Specificity of the antibody staining was confirmed by omitting the primary antibody.

Presence of eosinophils was evaluated morphologically by hematoxylin/eosin staining.

\section{Statistical analysis}

All values are expressed as mean \pm sd or median [range] in case of nonnormally distributed data. Normally distributed continuous variables were analyzed by a Student $t$ test. Non-normally distributed continuous data were analyzed with a Wilcoxon-Mann-Whitney test using SPSS 11.5 for Windows (SPSS, Chicago, Illinois, USA). CIA (Confidence Interval Analysis, v2.0.0. 41, T. Bryant, University of Southampton) was used to calculate the nonparametric $95 \%$ confidence interval for differences in mRNA expression. 


\section{Lindeman et al.}

Possible relationships between aneurysm diameter and inflammatory markers were evaluated by Pearson's correlation test. The level of statistical significance was set at $\mathrm{P}<0.05$. This study incorporates multiple statistical comparisons. For the sake of clarity non-corrected data is provided, yet a Bonferroni correction should be considered when interpreting non-correlated data. 


\section{Results}

1. Characterization of aneurismal and atherosclerotic aortic walls based on cytokine expression profiles

Aortic aneurismal (AAA) and atherosclerotic (ASD) wall biopsies used in this study were characterized for expression of markers of inflammation. RT-PCR and Bioplex analysis was used to determine the expression level of specific Th1associated, Th2-associated and general inflammatory factors on the mRNA and/or protein level.

Compared to ASD, the AAA group displayed significantly higher aortic mRNA expression levels of the Th1-associated transcription factor T-bet (24-fold increase) and the Th2-associated transcription factor GATA-3 (12-fold increase; Table 3). The Tbet/GATA3 ratio was similar in both experimental groups $(P=0.52)$.

A subsequent analysis of cytokines in aortic mRNA extracts revealed substantially increased mRNA levels of the Th1-associated cytokines IL-2, IFN- $\gamma$, TNF $\alpha$, IL-1 $\alpha$ and IL1 $\beta$ in AAA. In line with this observation, the protein levels of IL-2, IFN- $\gamma$, TNF $\alpha$ and IL- $1 \alpha$ were significantly elevated in aortic AAA homogenates (Table $4)$.

With respect to Th2-associated cytokines, higher mRNA levels of IL-4, IL-10 and IL-13 $(\mathrm{P}<0.01)$ were found in AAA (Table 3). An increase of IL-4 and IL-13 was also observed on the protein level, while IL-5 and IL-10 were below the detection limit of the Bioplex assay (Table 4).

In addition to these typical Th1- and Th2-associated factors, also cytokines/chemokines reflecting a general pro-inflammatory status such as MCP-1, MIP-1 $\beta$, MIF, G-CSF and GM-CSF were significantly higher expressed in AAA as compared to ASD (on mRNA and/or protein level; Table 3 and 4). 


\section{Lindeman et al.}

Together, the above molecular characterization of aortic wall biopsies (by cytokine profiling) does not indicate a clear Th1/Th2 polarization in AAA but points to a generic enhancement of inflammation compared to ASD.

\section{Characterization on basis of cellular markers of Th1/Th2 polarization.}

To further characterize AAA and ASD aortas, their cellular composition was evaluated with particular emphasis on Th1- and Th2-associated cellular responses.

Absolute and relative $T_{\text {cytotoxic }}$-cell infiltration (Th1-associated) was assessed by analyzing aortic CD4 and CD8 mRNA expression levels. [20] AAA displayed higher CD8 (26-fold, $P<0.001)$ and CD4 (12-fold, $P=0.24)$ mRNA expression levels and a higher CD8/CD4 ratio $(P<0.001)$ suggesting an enhanced influx of $\mathrm{T}_{\text {cytotoxic-cells in }}$ AAA tissue. Specific immunohistochemical (IHC) staining of $T_{\text {cytotoxic }}$-cells in crosssections prepared from AAA biopsy samples confirmed a higher abundance of

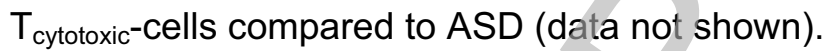

Potential Th2-related cellular effects were evaluated by IHC staining of B-cells (CD20) and assessment of eosinophil infiltration. AAA biopsies showed a dispersed CD20-immunoreactivity (IR) which was hardly observed in ASD (limited to infiltrates in the medial-adventitial transition zone in some ASD controls), clearly demonstrating enhanced B-cell infiltration in AAA (Figure $1 \mathrm{~A} / \mathrm{B}$ ). Eosinophils were not found in AAA and ASD (not shown).

The results of our cellular characterization are in line with the cytokine expression data and demonstrate overrepresentation of cells important for Th1-type and Th2-type responses. We next examined the downstream consequences by assessing the basal expression level and/or the activation status of relevant inflammatory transcription factors, i.e. transcription factors mainly involved in the 


\section{Lindeman et al.}

signal transduction of the cytokines expressed in AAA (C/EBP $\alpha, \mathrm{C} / \mathrm{EBP} \beta, \mathrm{C} / \mathrm{EBP} \delta$, $N F-k B, c-j u n(A P-1))$.

\section{Enhanced expression of (activated) pro-inflammatory transcription factors AAA}

AAA and ASD protein homogenates were prepared and subjected to Western blot analysis. Aortic transcription factor concentrations were quantified relative to $\beta$ actin. When compared to ASD, the aortic concentrations of the three isoforms C/EBP $\alpha$, C/EBP $\beta$, C/EBP $\delta$ were 6.3-fold, 3.1-fold, 4.2-fold higher $(P<0.05)$ in AAA, respectively (Figure 2A). Baseline p65-NF-kB and c-jun expression levels were comparable in AAA and ASD (Figure 2B), but the aortic wall concentrations of their activated forms p65-NF-kB $B_{\text {active }}$ and $\mathrm{p}$-c-jun were 3.7-fold and 3.3-fold (both $P<0.001$ ) higher in AAA as assessed by antibodies specifically detecting activated / phosphorylated epitopes (Figure 2B). Together these results demonstrate an enhanced pro-inflammatory status on the transcription factor level in AAA, despite enhancement of expression of cytokines with anti-inflammatory properties (e.g. IL-10).

\section{Enhanced IL-6 and IL-8 expression AAA}

We next examined whether inflammatory factors that are positively regulated by C/EBPs, p65-NF-KB and $\mathrm{C}-\mathrm{jun}$ are also elevated in AAA when compared to ASD. IL-8 transcription and IL-6 expression rely on concomitant activation of signalling pathways activating NF-KB and AP-1 (i.e. c-jun) or NF-kB and C/EBPs. [21,22]

Indeed, IL-6 and IL-8 mRNA expression was strongly and significantly elevated in AAA as compared to ASD (Table 5). Analysis of IL-6 and IL-8 expression levels in AAA and ASD tissue homogenates by ELISA confirmed that AAA contained very large amounts of IL-6 and IL-8 (Figure 3A). IL-6 and IL-8 levels exceeded the levels of all 


\section{Lindeman et al.}

other cytokines determined in AAA and were more than 100 -fold increased $(P<0.001)$ compared to ASD. No relationship was found between the IL-6 or IL-8 level and the aneurysm diameter.

Hyperexpression of IL-6 and IL-8 clearly demonstrates an inflammatory divergence between AAA and ASD. IHC analysis of IL-6 and IL-8 expression (Figure 3B) confirmed abundant expression of both cytokines in AAA. Of note, IL-6 and IL-8 immunoreactivity (IR) in AAA was dispersed throughout all layers of the aortic wall and not essentially confined to the intimal layer and intimal border zone of the media as in ASD. Refined analysis of the cell types expressing IL-6 and IL-8 in AAA revealed that IL-6-IR was predominantly associated with plasma cells and macrophages while IL-8IR was mainly associated with lymphocytes and neutrophils. IL-6 and IL-8 IR in ASD on the other hand was predominantly limited to foam cells/macrophages, vascular smooth muscle cells and lymfocytes. Altogether these data demonstrate a transmural hyperexpression of IL-6 and IL-8 in AAA.

\section{Examination of molecular and cellular effects downstream of IL-6}

IL-6 mediated responses depend on the availability of cell-bound IL-6R or soluble IL-6R (sIL-6R). sIL-6R can induce IL-6 signalling in cells not constitutively expressing IL-6R (IL-6 trans-signalling) but its receptor dimer, gp130. [23] Figure 4A demonstrates that sIL-6R is present in the aortic wall, and that levels are comparable in AAA and ASD. Quantification of p-STAT3, a downstream transcriptional effector of IL-6, showed that AAA wall contained higher levels of p-STAT3 (20-fold increased; $P<0.01$ ) than ASD (Figure 4B). The protein levels of the inactive form (unphosphorylated STAT-3) of this transcription factor were lower in AAA (Figure 4B). 


\section{Lindeman et al.}

Together, these data indicate that hyperexpression of IL-6 in AAA is associated with elevated levels of p-STAT3, i.e. enhanced IL-6 signalling.

Well-established functional downstream effects (read-outs) of IL-6 include the differentiation/maturation of B-cells into plasma cells and the activation of $\mathrm{T}_{\text {cytotoxic }}$ cells. Evaluation of the plasma cell content in AAA and ASD using $\mathrm{IHC}$ demonstrated an abundance of plasma cells in AAA wall, whereas plasma cell-specific IR (CD138) was not or hardly present in ASD (Figure 1C and D). Expression of perforin, a factor which indicates $T_{\text {cytotoxic }}$-cell activation, was significantly elevated in AAA, both on the transcriptional level (13-fold, $\mathrm{P}=0.006$; not shown) and the protein expression level (Figure 4C).

\section{Examination of molecular and cellular effects downstream of IL-8}

IL-8 strongly promotes neutrophil infiltration and activation, and can exert strong pro-angiogenic activities. Quantification of infiltrated neutrophils by IHC staining of myeloperoxidase demonstrated a pronounced recruitment of these cells in AAA but only scattered presence of neutrophils in the adventitial layer of ASD (Figure $1 \mathrm{E}$ and F).

To examine whether AAA is also associated with increased pro-angiogenic responses, we quantified the number of vasa vasorum in AAA and ASD. Doubling of the number of vasa vasorum $\left(9 / \mathrm{mm}^{2}\right.$ in AAA versus $4 / \mathrm{mm}^{2}$ in ASD) points to an enhanced angiogenic response in AAA (not shown). 


\section{Discussion}

In this study, we set out to determine the aortic levels of inflammatory cytokines in relation to downstream inflammatory transcription factors and cellular responses in human aortic abdominal aneurysm (AAA). Comparison of growing AAA to atherosclerotic disease (ASD) using biopsies taken from the same aortic region allowed us to define inflammatory characteristics of AAA that distinguish this disease from ASD.

The results from this study demonstrate an enhanced expression of factors associated with both Th1-type and Th2-type responses in AAA. Our data do therefore not support a clear Th1 or Th2 polarization in AAA. On the transcription factor level, AAA clearly differs from ASD by displaying higher concentrations of the proinflammatory transcription factors $\mathrm{C} / \mathrm{EBP} \alpha, \mathrm{C} / \mathrm{EBP} \beta, \mathrm{C} / \mathrm{EBP} \delta$, and the activated forms of p65-NF-kB and c-jun, a component of $A P-1$. In line with this, $A A A$ is characterized by hyperexpression of IL-6 and IL-8, both of which positively regulated by NF-кB and AP-1. We demonstrate that molecular and cellular processes that are associated with hyperactivation of IL- 6 and IL- 8 are exaggerated in AAA: the aortic $p$ STAT-3 and perforin concentrations are elevated in AAA wall, and B cells, plasma cells, neutrophils are abundantly present in AAA, clearly distinguishing this pathology from ASD.

The large majority of patients with AAA also suffer from advanced atherosclerotic disease, and AAA has long been considered to be one of the classical manifestations of atherosclerotic disease. Yet, traditional atherosclerotic risk factors such as cholesterol and diabetes are not associated with AAA [24], suggesting that AAA may be a separate entity. Although AAA and ASD share an inflammatory component relevant for disease evolution, the exact molecular processes causatively 


\section{Lindeman et al.}

involved in progression of human AAA or ASD are not fully understood. Also, clear-cut mechanistic differences allowing discriminating AAA from ASD have not been identified so far.

Recent studies assessing the aortic expression of Th1-specific and Th2-specific inflammatory mediators in human AAA report controversial observations and claim a predominance of either Th1-type or Th2-type responses in human AAA. $[3,10,11]$ Our findings do not support a clear Th1/Th2 polarization in AAA and indicate an upregulation of both immune cell responses (as compared to ASD), together with a profound general inflammatory response which is characterized by high expression of cytokines, chemokines and growth factors (e.g. MCP-1, MIF, TGF $\beta$, MIP-1 $\beta$ and GCSF). Our observations are in accordance with a recent protein array study by Middleton and coworkers [12] who characterize AAA as a classical inflammatory condition which is dominated by a generic inflammatory response involving similar pro-inflammatory (e.g. IL-1 $\beta$, TNF $\alpha$ ) and anti-inflammatory cytokines (e.g. IL-10). [25]

The net effect of these effects on the downstream transcription factor level has not been investigated so far. Our data demonstrate for the first time that the aortic concentrations of major inflammatory transcription factors at baseline $(\mathrm{C} / \mathrm{EBP} \alpha$, $\mathrm{C} / \mathrm{EBP} \beta, \mathrm{C} / \mathrm{EBP} \delta$ ) or their activated forms (p65-NF- $\kappa \mathrm{B}_{\text {active }}$ and $\mathrm{p}-\mathrm{c}-\mathrm{jun}$ ) are strongly elevated in AAA relative to ASD. Elevated aortic levels of $p-c-j u n$ are in accordance with an increased activation of JNK in AAA as reported recently. [26] Since IL-8 and IL-6 gene expression depend on simultaneous activation of NF-kB and AP-1, [21,22] the aortic concentrations of these cytokines in AAA and ASD were examined on gene transcription level. Indeed, IL-6 and IL-8 mRNA was markedly elevated in AAA and this was paralleled by a strong elevation of IL- 6 and IL-8 protein. High aortic expression levels of IL- 6 and IL-8 in human AAA have also been reported by others, 
$[14,27,28]$ but the extreme disparity compared to atherosclerotic disease has not been recognized so far. The hyperexpression of IL-6 and IL-8 in AAA observed herein thus constitutes an important difference between the pathologies AAA and ASD.

Predominance of IL-6 and IL-8 in growing AAA, and responses mediated by these cytokines point to a central role of these factors in the development of AAA.

IL-6 is a well recognized inducer of the hepatic acute phase response and a possible cardiovascular risk factor. [29] Because the receptor of IL-6, IL-6R, is predominantly expressed by hepatocytes and leukocytes, an extrahepatic role of IL-6 was uncertain. With the discovery of a soluble form of IL-6R allowing 'IL-6 transsignalling' in cells normally not bearing the IL-6R, [23] IL-6 has gained importance for vascular disease, and in atherosclerosis IL-6 has been associated with lipid homeostasis, vascular remodelling and plague remodelling. [30] Our data demonstrate that sIL-6R is expressed in aortic AAA and ASD walls to a comparable extent. We also demonstrate that a key mediator and downstream effector of IL-6, STAT-3, is present in aorta together with its activated (phosphorylated) form, $p$ STAT3. We show that the large differences in IL-6 protein expression in AAA and ASD are paralleled on the downstream transcription factor level: AAA walls contain higher p-STAT- 3 concentrations than ASD, pointing to a pronounced activation of the IL-6 (trans)signalling route in AAA.

Increased IL-6 (trans)signalling may at least partly explain the differences in cellular composition seen in AAA and ASD wall biopsies. IL-6 reportedly controls late B-cell differentiation and plasma cell formation, and is an established promoter of Tcell migration, retention and activation. [31,32] Enhanced activation of the IL-6 route may very well be responsible for the abundant infiltration of B-cells observed by us and others. [14,33] Furthermore, our histological data indicate a strong abundance of 


\section{Lindeman et al.}

plasma cells (plasmacytosis) in AAA suggesting a higher B-cell differentiation rate [34] Analysis of CD4 and CD8 expression indicates mainly increased infiltration of

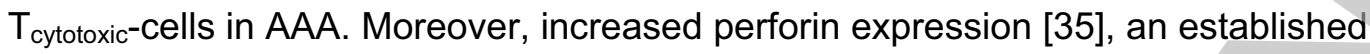
marker of $T_{\text {cytotoxic }}$-cell activation, demonstrates an elevated $T_{\text {cytotoxic }}$-cell activation status in AAA as compared to ASD, which is in line with the observation that apoptosis is enhanced in AAA. [36]

Increased IL-8 expression has been reported in several inflammatory conditions, including Kawasaki's disease [37] and Behçet disease, [38] two conditions that are associated with aneurysm formation. In line with this, expression of IL-8 in aortic aneurismal tissue has been described. $[12,28]$ To our knowledge, the hyperexpression of IL-8 associated with neutrophil cell infiltration in AAA observed in this study, has not been reported so far and suggests that neutrophils infiltration is a hallmark of AAA allowing the discrimination of AAA and ASD. Furthermore, G-CSF, the simultaneous expression of which facilitates IL-8-dependent neutrophil cell recruitment, [39] was highly expressed in AAA, but not in ASD. It is tempting to speculate that the concomitant expression of these factors is responsible for the neutrophil infiltration that appears critical for the process of aneurysm formation. $[40,41]$

In summary, our data demonstrate that inflammation in AAA wall is clearly distinct from inflammation in ASD and that IL-6 and IL-8 hyperexpression and dominance of IL-6 and IL-8 mediated responses prevail in AAA. This comprehensive inflammatory response in AAA may well be responsible for the broad, albeit not universal, upregulation of selective members of the MMP class of proteases $[2,16]$ (MMP-8 (neutrophil-derived) and MMP-9 (AP-1 regulated [26] )), and the cysteine proteases cathepsin K, L and S [16] (NFKB, [42] C/EBP [43] and interferon $\gamma$ [44] 


\section{Lindeman et al.}

regulated respectively) in the disease. Anti-inflammatory strategies attenuating IL-6 and IL-8 expression or activity, [26] and/or IL-6 and IL-8 signalling may prove effective for the pharmaceutical stabilization of AAA. 


\section{References}

${ }^{1}$ Sakalihasan N, Limet R, Defawe OD. (2005) Abdominal aortic aneurysm. Lancet. 365, 1577-89

2 Thompson RW, Geraghty PJ, Lee JK. (2002) Abdominal aortic aneurysms: basic mechanisms and clinical implications. Curr Probl Surg. 39, 110-230

${ }^{3}$ Shimizu K, Mitchell RN, Libby P. (2006) Inflammation and cellular immune responses in abdominal aortic aneurysms. Arterioscler Thromb Vasc Biol. 26, 987-994

${ }^{4}$ Koch AE, Haines GK, Rizzo RJ, Radosevich JA, Pope RM, Robinson PG, Pearce WH. (1990) Human abdominal aortic aneurysms. Immunophenotypic analysis suggesting an immune-mediated response. Am J Pathol. 137, 1199-1213

${ }^{5}$ Jacob T, Ascher E, Hingorani A, Gunduz Y, Kallakuri S. (2001) Initial steps in the unifying theory of the pathogenesis of artery aneurysms. J Surg Res. 101, 37-43

${ }^{6}$ Nagashima H, Aoka Y, Sakomura Y, Sakuta A, Aomi S, Ishizuka N, Hagiwara N, Kawana M, Kasanuki H. (2002) A 3-hydroxy-3-methylglutaryl coenzyme A reductase inhibitor, cerivastatin, suppresses production of matrix metalloproteinase-9 in human abdominal aortic aneurysm wall. J Vasc Surg. 36, 158-163

${ }^{7}$ Bouma G, Strober W. (2003) The immunological and genetic basis of inflammatory bowel disease. Nat Rev Immunol. 3, 521-533

${ }^{8}$ Tipping PG, Kitching AR. (2005) Glomerulonephritis, Th1 and Th2: what's new? Clin Exp Immunol. 142, 207-215

${ }^{9}$ Murphy KM, Reiner SL. (2002) The lineage decisions of helper T cells. Nat Rev Immunol. 2, 933-944

${ }^{10}$ Galle C, Schandene L, Stordeur P, Peignois Y, Ferreira J, Wautrecht JC, Dereume JP, Goldman M. (2005) Predominance of type 1 CD4+ T cells in human abdominal aortic aneurysm. Clin Exp Immunol.

$142,519-527$

11 Schonbeck U, Sukhova GK, Gerdes N, Libby P. (2002) T(H)2 predominant immune responses prevail in human abdominal aortic aneurysm. Am J Pathol. 161, 499-506

${ }^{12}$ Middleton RK, Lloyd GM, Bown MJ, Cooper NJ, London NJ, Sayers RD. (2007) The pro-inflammatory and chemotactic cytokine microenvironment of the abdominal aortic aneurysm wall: a protein array study. J Vasc Surg. 45, 574-580

${ }^{13}$ Shteinberg D, Halak M, Shapiro S, Kinarty A, Sobol E, Lahat N, Karmeli R. (2000) Abdominal aortic aneurysm and aortic occlusive disease: a comparison of risk factors and inflammatory response. Eur $\mathrm{J}$ Vasc Endovasc Surg. 20, 462-465

14 Treska V, Kocova J, Boudova L, Neprasova P, Topolcan O, Pecen L, Tonar Z. (2002) Inflammation in the wall of abdominal aortic aneurysm and its role in the symptomatology of aneurysm. Cytokines Cell Mol Ther. 7, 91-97

${ }^{15}$ Stary HC, Chandler AB, Dinsmore RE, Fuster V, Glagov S, Insull Jr. W, Rosenfeld ME, Schwartz CJ, Wagner WD, Wissler RW. (1995) A definition of advanced types of atherosclerotic lesions and a histological classification of atherosclerosis. A report from the Committee on Vascular Lesions of the Council on Arteriosclerosis, American Heart Association. Arterioscler Thromb Vasc Biol. 15, 1512-1531 
${ }^{16}$ Abdul-Hussien H, Soekhoe RG, Weber E, von der Thusen JH, Kleemann R, Mulder A, van Bockel $\mathrm{JH}$, Hanemaaijer R, Lindeman JHN. (2007) Collagen degradation in the abdominal aneurysm: a conspiracy of matrix metalloproteinase and cysteine collagenases. Am J Pathol. 170, 809-817

${ }^{17}$ Kleemann R, Gervois PP, Verschuren L, Staels B, Princen HM, Kooistra T. (2003) Fibrates downregulate IL-1-stimulated C-reactive protein gene expression in hepatocytes by reducing nuclear p50NFkappa B-C/EBP-beta complex formation. Blood. 101, 545-551

${ }^{18}$ Gervois P, Kleemann R, Pilon A, Percevault F, Koenig W, Staels B, Kooistra T. (2004) Global suppression of IL-6-induced acute phase response gene expression after chronic in vivo treatment with the peroxisome proliferator-activated receptor-alpha activator fenofibrate. JBiol Chem. 279, 1615416160

${ }^{19}$ Verschuren L, Lindeman JH, van Bockel JH, Abdul-Hussien H, Kooistra T, Kleemann R. (2005) Upregulation and coexpression of MIF and matrix metalloproteinases in human abdominal aortic aneurysms. Antioxid Redox Signal. 7, 1195-1202

${ }^{20}$ Mocellin S, Provenzano M, Rossi CR, Pilati P, Nitti D, Lise M. (2003) Use of quantitative real-time PCR to determine immune cell density and cytokine gene profile in the tumor microenvironment. J Immunol Methods. 280, 1-11

${ }^{21}$ Roebuck KA. (1999) Regulation of interleukin-8 gene expression. J Interferon Cytokine Res. 19, 429438

22 Vanden Berghe W, De Bosscher K, Boone E, Plaisance S, Haegeman G. (1999) The nuclear factorkappaB engages CBP/p300 and histone acetyltransferase activity for transcriptional activation of the interleukin-6 gene promoter. J Biol Chem. 274, 32091-32098

${ }^{23}$ Scheller J, Rose-John S. (2006) Interleukin-6 and its receptor: from bench to bedside. Med Microbiol Immunol (Berl). 195, 173-183

${ }^{24}$ Cornuz J, Sidoti Pinto C, Tevaearai H, Egger M. (2004) Risk factors for asymptomatic abdominal aortic aneurysm: systematic review and meta-analysis of population-based screening studies. Eur $\mathrm{J}$ Public Health. 14, 343-349

${ }^{25}$ Menger MD, Vollmar B. (2004) Surgical trauma: hyperinflammation versus immunosuppression? Langenbecks Arch Surg. 389, 475-484

${ }^{26}$ Yoshimura K, Aoki H, Ikeda Y, Fujii K, Akiyama N, Furutani A, Hoshii Y, Tanaka N, Ricci R, Ishihara T, Esato K, Hamano K, Matsuzaki M. (2005) Regression of abdominal aortic aneurysm by inhibition of c-Jun N-terminal kinase. Nat Med. 11, 1330-1338

${ }^{27}$ Shteinberg D, Halak M, Shapiro S, Kinarty A, Sobol E, Lahat N, Karmeli R. (2000) Abdominal aortic aneurysm and aortic occlusive disease: a comparison of risk factors and inflammatory response. Eur $\mathrm{J}$ Vasc Endovasc Surg. 20, 462-465

${ }^{28}$ Koch AE, Kunkel SL, Pearce WH, Shah MR, Parikh D, Evanoff HL, Haines GK, Burdick MD, Strieter RM. (1993) Enhanced production of the chemotactic cytokines interleukin-8 and monocyte chemoattractant protein-1 in human abdominal aortic aneurysms. Am J Pathol. 142, 1423-1431

${ }^{29}$ Lee WY, Allison MA, Kim DJ, Song CH, Barrett-Connor E. (2007) Association of interleukin-6 and Creactive protein with subclinical carotid atherosclerosis (the Rancho Bernardo Study). Am J Cardiol. 99, 99-102 
${ }^{30}$ Tedgui A, Mallat Z. (2006) Cytokines in atherosclerosis: pathogenic and regulatory pathways. Physiol Rev. 86, 515-581

${ }^{31}$ Gabay C. (2006) Interleukin-6 and chronic inflammation. Arthritis Res Ther. 8 Suppl 2, S3

${ }^{32}$ McLoughlin RM, Jenkins BJ, Grail D, Williams AS, Fielding CA, Parker CR, Ernst M, Topley N, Jones SA. (2005) IL-6 trans-signalling via STAT3 directs T cell infiltration in acute inflammation. Proc Natl Acad Sci U S A. 102, 9589-9594

${ }^{33}$ Forester ND, Cruickshank SM, Scott DJ, Carding SR. (2005) Functional characterization of T cells in abdominal aortic aneurysms. Immunology. 115, 262-270

${ }^{34}$ Klein B, Tarte K, Jourdan M, Mathouk K, Moreaux J, Jourdan E, Legouffe E, De Vos J, Rossi JF. (2003) Survival and proliferation factors of normal and malignant plasma cells. Int J Hematol. 78, 106113

${ }^{35}$ Andersen MH, Schrama D, Thor Straten P, Becker JC. (2006) Cytotoxic T cells. J Invest Dermatol. 126, 32-41

${ }^{36}$ Henderson EL, Geng YJ, Sukhova GK, Whittemore AD, Knox J, Libby P. (1999) Death of smooth muscle cells and expression of mediators of apoptosis by $\mathrm{T}$ lymphocytes in human abdominal aortic aneurysms. Circulation. 99, 96-104

${ }^{37}$ Lin CY, Lin CC, Hwang B, Chiang BN. (1993) Cytokines predict coronary aneurysm formation in Kawasaki disease patients. Eur J Pediatr. 152, 309-312

${ }^{38}$ Keller M, Spanou Z, Schaerli P, Britschgi M, Yawalkar N, Seitz M, Villiger PM, Pichler WJ. (2005) T cell-regulated neutrophilic inflammation in autoinflammatory diseases. J Immunol. 175, 7678-7686.

${ }^{39}$ Cataisson C, Pearson AJ, Tsien MZ, Mascia F, Gao JL, Pastore S, Yuspa SH. (2006) CXCR2 ligands and G-CSF mediate PKCalpha-induced intraepidermal inflammation. J Clin Invest. 116, 2757-2766 ${ }^{40}$ Eliason JL, Hannawa KK, Ailawadi G, Sinha I, Ford JW, Deogracias MP, Roelofs KJ, Woodrum DT, Ennis TL, Henke PK, Stanley JC, Thompson RW, Upchurch GR Jr. (2005) Neutrophil depletion inhibits experimental abdominal aortic aneurysm formation. Circulation. 112, 232-240

${ }^{41}$ Pagano MB, Bartoli MA, Ennis TL, Mao D, Simmons PM, Thompson RW, Pham CT. (2007) Critical role of dipeptidyl peptidase I in neutrophil recruitment during the development of experimental abdominal aortic aneurysms. Proc Natl Acad Sci U S A. 104, 2855-2860

${ }^{42}$ Pang M, Martinez AF, Jacobs J, Balkan W, Troen BR. (2005) RANK ligand and interferon gamma differentially regulate cathepsin gene expression in pre-osteoclastic cells. Biochem Biophys Res Commun. 328, 756-763

43 Jean D, Guillaume N, Frade R. (2002) Characterization of human cathepsin L promoter and identification of binding sites for NF-Y, Sp1 and Sp3 that are essential for its activity. Biochem J., $\mathbf{3 6 1}$, 173-84

${ }^{44}$ Maubach G, Lim MC, Kumar S, Zhuo L. (2007) Expression and upregulation of cathepsin S and other early molecules required for antigen presentation in activated hepatic stellate cells upon IFN-gamma treatment. Biochim Biophys Acta. 1773, 219-231 


\section{Lindeman et al.}

Table 1. TaqMan ${ }^{\circledR}$ Gene Expression Assays (Applied Biosystems), or probe primer combinations (IL-6 and MIF) used in the RealTime PCR.

\begin{tabular}{|c|c|}
\hline T-bet & Hs00203436_m1 \\
\hline GATA-3 & Hs00231122_m1 \\
\hline IL-1 $\alpha$ & Hs00174092_m1 \\
\hline IL-1 & Hs00174097_m1 \\
\hline IL-2 & $\mathrm{Hs} 00174114-\mathrm{m} 1$ \\
\hline IL-4 & Hs00174122_m1 \\
\hline IL-8 & Hs00174103_m1 \\
\hline IL-10 & Hs00174086_m1 \\
\hline IL-13 & Hs00174379_m1 \\
\hline Interferon- $\mathrm{Y}$ & Hs00174143_m1 \\
\hline TNF- $\alpha$ & Hs00174128_m1 \\
\hline MCP-1 & Hs00234140_m1 \\
\hline MIP-1 $\beta$ & Hs99999148_m1 \\
\hline TGF $\beta$ & Hs99999918_m1 \\
\hline IL-6 & $\begin{array}{l}F^{\prime}: 5^{\prime} \text {-TGT AGC CGC CCC ACA CA-3' } \\
\text { R : 5'-AGA TGC CGT CGA GGA TGT ACC-3' } \\
\text { P: 5 -AGC CAC TCA CCT CTT CAG AAC GAA TTG ACA A-3' }\end{array}$ \\
\hline & $\begin{array}{l}\text { F: 5'-TGG CCG AGC GCC TG-3' } \\
\text { R: 5'-GCC GCG TTC ATG TCG TAA TA-3' } \\
\text { P: 5'-FAM-CAT CAG CCC GGA CAG GGT CTA CAT CA-3' }\end{array}$ \\
\hline
\end{tabular}

$f=$ forward, $r=$ reverse, $p=p r o b e$ 
Lindeman et al.

Table 2. Patient characteristics

\begin{tabular}{l|ll} 
& AAA & ASD \\
\hline $\mathrm{n}$ & 15 & 11 \\
Mean Age (years) & $72.4 \pm 6.2$ & $55.6 \pm 10.2$ \\
AAA diameter (cm) & $6.7 \pm 1.1$ & $<2.0$ \\
Female sex $(\mathrm{n})$ & 3 & 4 \\
Statin use $(\mathrm{n})$ & 1 & 1
\end{tabular}




\section{Lindeman et al.}

\section{Table 3. Fold differences in gene expression of markers of Th1-associated,}

\section{Th2-associated and general inflammatory responses.}

Messenger RNA expression was analyzed in aneurismal wall (AAA; $n=17)$ and athero-sclerotic wall (ASD; $n=11)$. Gene expression level of the measured genes in ASD was set at 1, and relative gene expression levels in AAA tissues are expressed as median fold increase together with the corresponding $95 \%$ confidential interval (Cl) of the median fold increase and the $P$-value. The corresponding $\Delta \mathrm{Ct}$ values for AAA and ASD are presented as mean (SD) (for normally distributed data) or as median [range] (for not normally distributed data). High (low) $\Delta$ Ct values reflect low (high) mRNA expression levels. A $\Delta \mathrm{Ct}$ value of 20 represents the detection limit of the assay. 


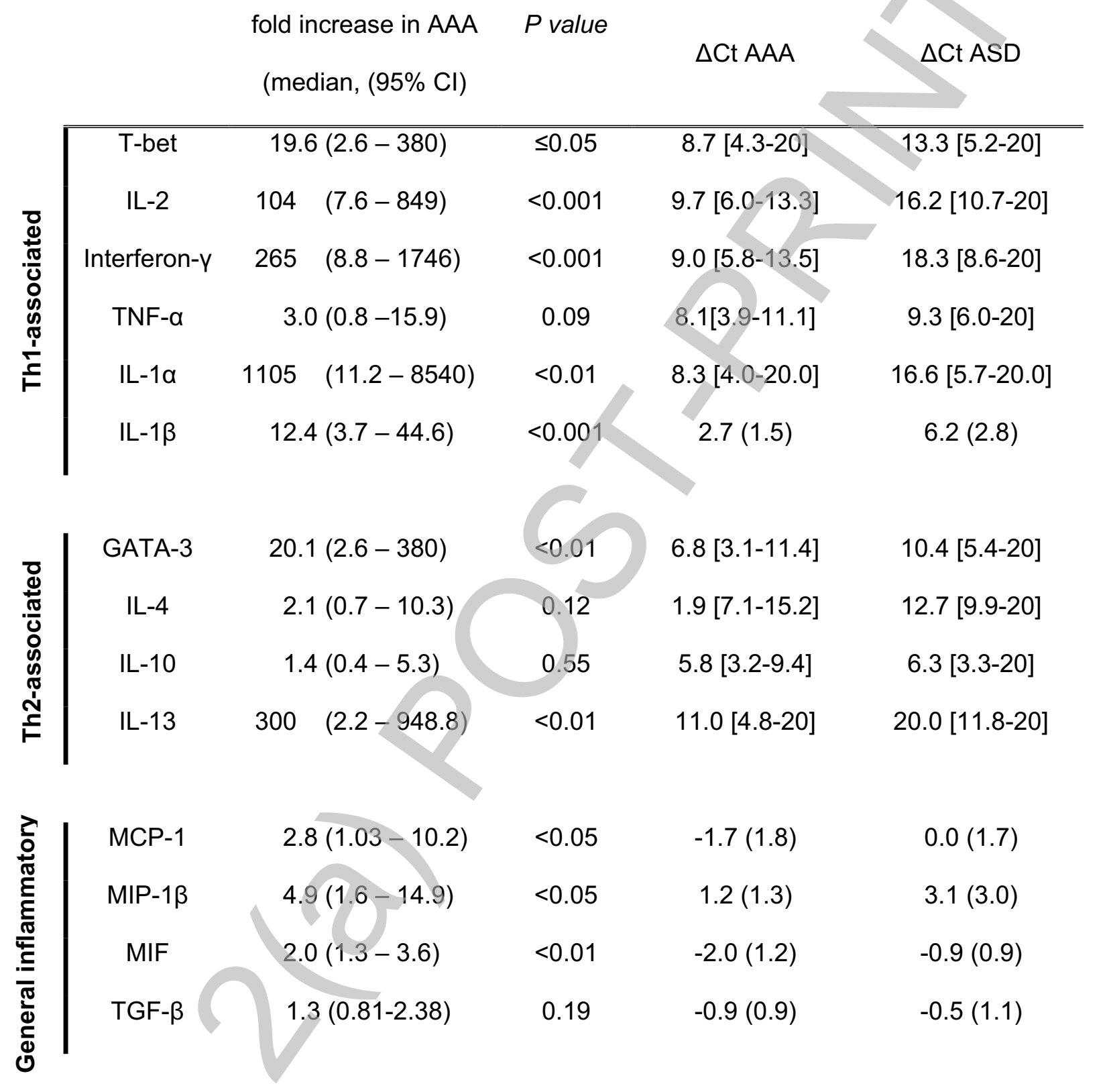

Note: The level of mRNA expression for each gene of interest was calculated using the $\mathrm{Ct}$ values. $\mathrm{Ct}$ values are defined as the number of PCR cycles at which the fluorescent signal generated during the PCR reaches a fixed threshold. For each sample, the Ct for the target gene and for the housekeeping gene was determined to calculate $\Delta \mathrm{Ct}\left(\mathrm{C}_{\mathrm{t}}\right.$, target gene $-\mathrm{C}_{\mathrm{t}}$, housekeeping gene). The relative expression of a gene can be calculated from the formula $2^{-\Delta \mathrm{Ct}}$. 


\section{Lindeman et al.}

Table 4. Differences in protein expression of markers of Th1-associated, Th2associated and general inflammatory responses. Aortic wall protein expression levels of markers of Th1-associated, Th2-associated and general inflammatory responses were determined in aneurismal wall $(A A A ; n=14)$ and atherosclerotic wall (ASD; $n=11$ ) samples using a Bio-Plex assay (MCP-1 by ELISA). Data are presented as median [range] and as $\mathrm{ng} / \mathrm{mg}$ total aortic protein. ND indicates not detectable (i.e. below the detection limit of the Bio-Plex assay). NA: not applicable.

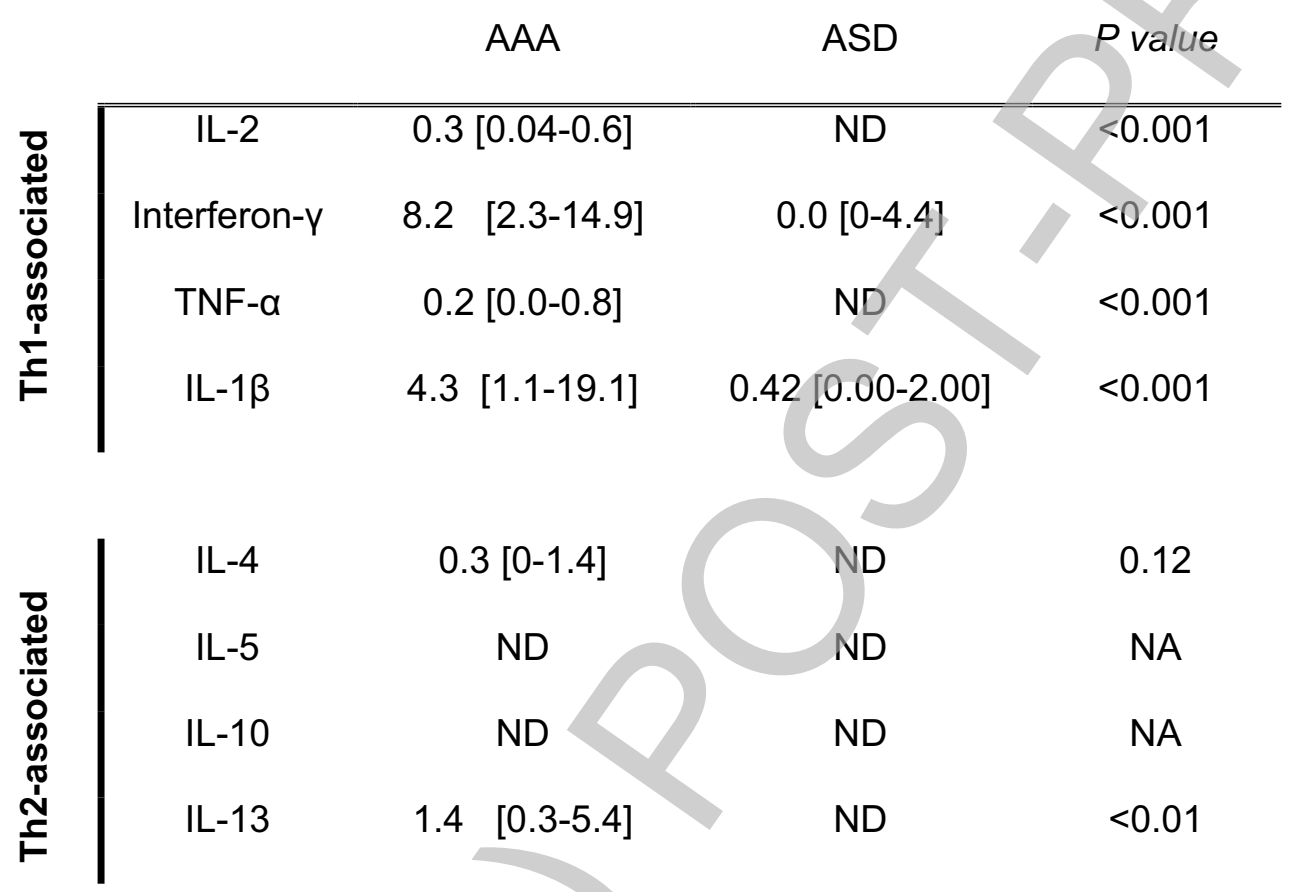

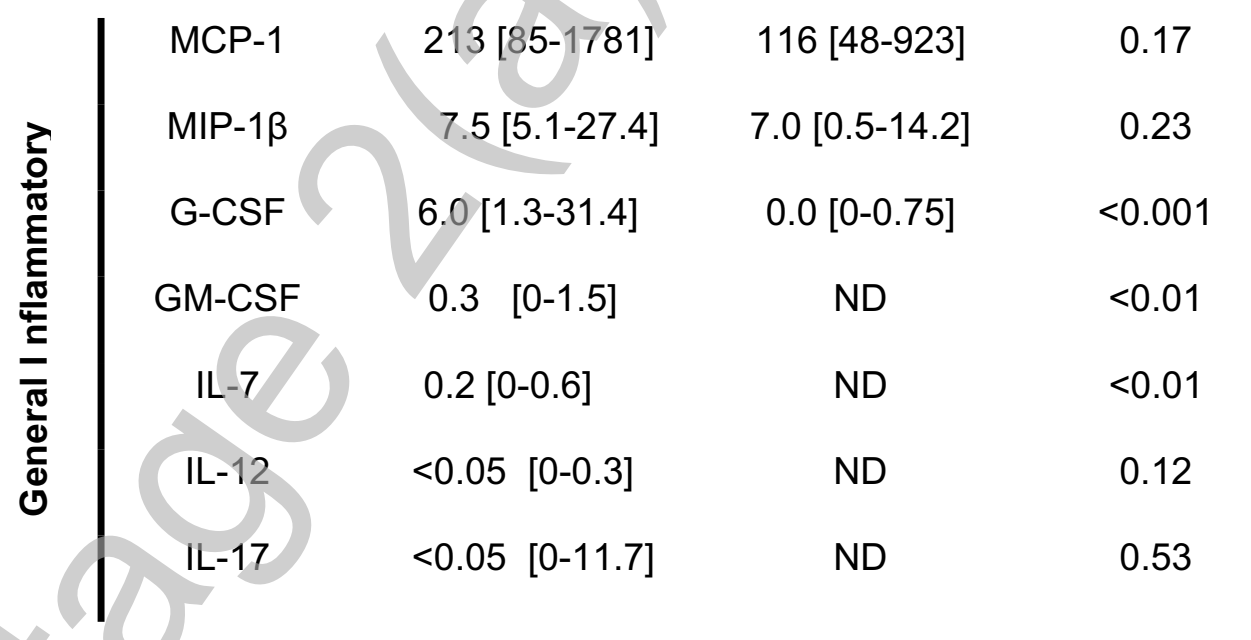




\section{Lindeman et al.}

Table 5. Elevation of IL-6 and IL-8 gene and protein expression in AAA.

Messenger RNA expression of IL-6 and IL-8 was analyzed in aneurismal wall (AAA; $n=17)$ and atherosclerotic wall (ASD; $n=12$ ) samples. The gene expression level of the measured genes in ASD was set at 1, and relative gene expression levels in AAA tissues are expressed as median fold increase together with the corresponding 95\% confidential interval $(\mathrm{Cl})$ of the median fold increase and the $P$-value. The mean $\Delta \mathrm{Ct}$ values (together with [range]) are provided in the last two columns. High (low) $\Delta \mathrm{Ct}$ values reflect low (high) mRNA expression levels.

\section{RNA level}

\begin{tabular}{|ccccc} 
& $\begin{array}{c}\text { fold increase in AAA } \\
\text { (median, }(95 \% \text { Cl) }\end{array}$ & A value & AAA & \\
\hline & & & & \\
\hline IL-6 & $29.9(10.9-86.8)$ & 0.001 & $2.8(1.7)$ & $7.7(2.0)$ \\
IL-8 & $21.1(3.48-65.3)$ & 0.003 & $1.4(2.1)$ & $5.8(4.5)$
\end{tabular}


Figure 1. Immunohistochemical analysis of cellular composition of AAA and ASD tissue. Representative photomicrographs (similar magnification) of ASD tissue (left) and AAA tissue (right) stained with an antibodies specifically detecting $A / B, B-$ lymphocytes (B-cells; anti-CD20), C/D, plasma cells (anti-CD138) and E/F, neutrophils (MPO). The scale bar represents $100 \mu \mathrm{m}$.

Figure 2. Elevated aortic concentrations of inflammatory transcription factors are characteristic for AAA wall. Basal levels of $\mathbf{A}, \mathrm{C} / \mathrm{EBP} \alpha, \mathrm{C} / \mathrm{EBP} \beta, \mathrm{C} / \mathrm{EBP} \delta$, and B, p65-NF-kB, c-jun protein and their activated forms (NF-kB active and p-c-jun) were determined by Western blotting in homogenates of AAA and ASD. (Transcription factor expression was determined relative to $\beta$-actin for each sample.) Data are presented in boxplots (median values, lower and upper quartiles, and range), ${ }^{*} P<$ 0.001 .

Figure 3. Elevated aortic concentrations of IL-6 and IL-8 protein are characteristic for AAA wall. A, Aortic wall protein expression levels of IL-6 and IL-8 were determined by specific ELISAs in aneurismal wall (AAA; $n=14$ ) and atherosclerotic wall (ASD; $n=12)$ samples. Data are presented in boxplots as median, lower and upper quartiles, and range, ${ }^{*} P<0.0001$. B, Representative photomicrographs (similar magnification) of ASD tissue (left) and AAA tissue (right) stained with antibodies specifically detecting IL-6 or IL-8. IL-6-immunoreactivity (IR) was associated with plasma cells and with macrophages; IL-8-IR was associated with lymphocytes and neutrophils based morphological characteristics. The scale bar represents $100 \mu \mathrm{m}$. 
Lindeman et al.

Figure 4. Assessment of functional components of the IL-6 signalling route in AAA and ASD. A, Aortic wall protein expression levels of soluble IL-6 receptor (sIL$6 R$ ) was determined by ELISA in aneurismal wall (AAA; $n=14)$ and atherosclerotic wall (ASD; $n=12$ ) samples. B, Basal levels of STAT3 protein and levels of the activated forms p-STAT3 were determined by Western blotting in homogenates of AAA and ASD. (Transcription factor expression was determined relative to $\beta$-actin.) Data are presented in boxplots (median values, lower and upper quartiles, and range), ${ }^{*} P<0.0001$. C, Aortic wall protein expression levels of perforin was determined by ELISA in aneurismal wall (AAA; $n=14$ ) and atherosclerotic wall (ASD; $n=12$ ) samples. Elevated perforin protein levels in AAA indicate increased $T_{\text {cytotoxic }}$ cell activation in AAA. Median values are indicated in the boxplots, ${ }^{*} P<0.001$. 


\section{Figure 1.}

\section{ASD}
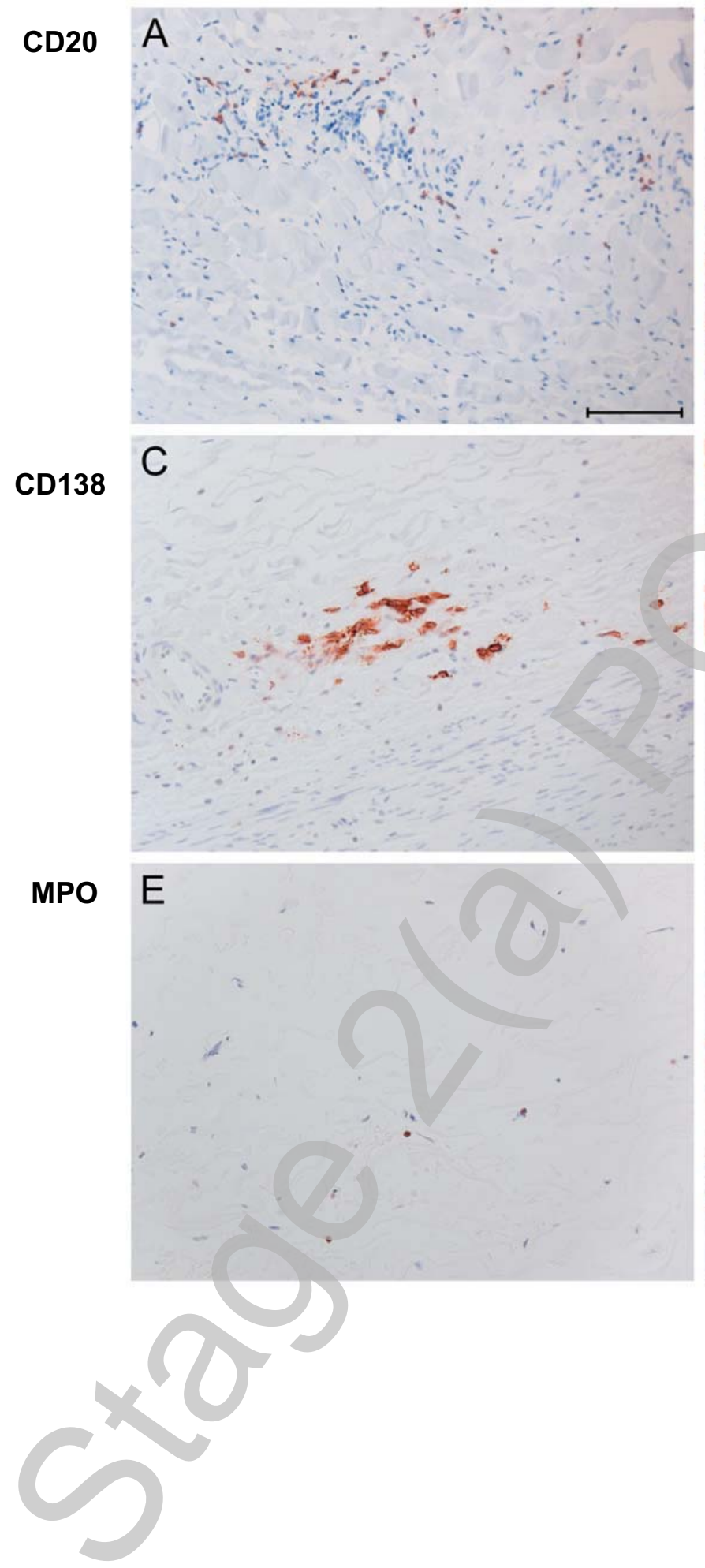

AAA
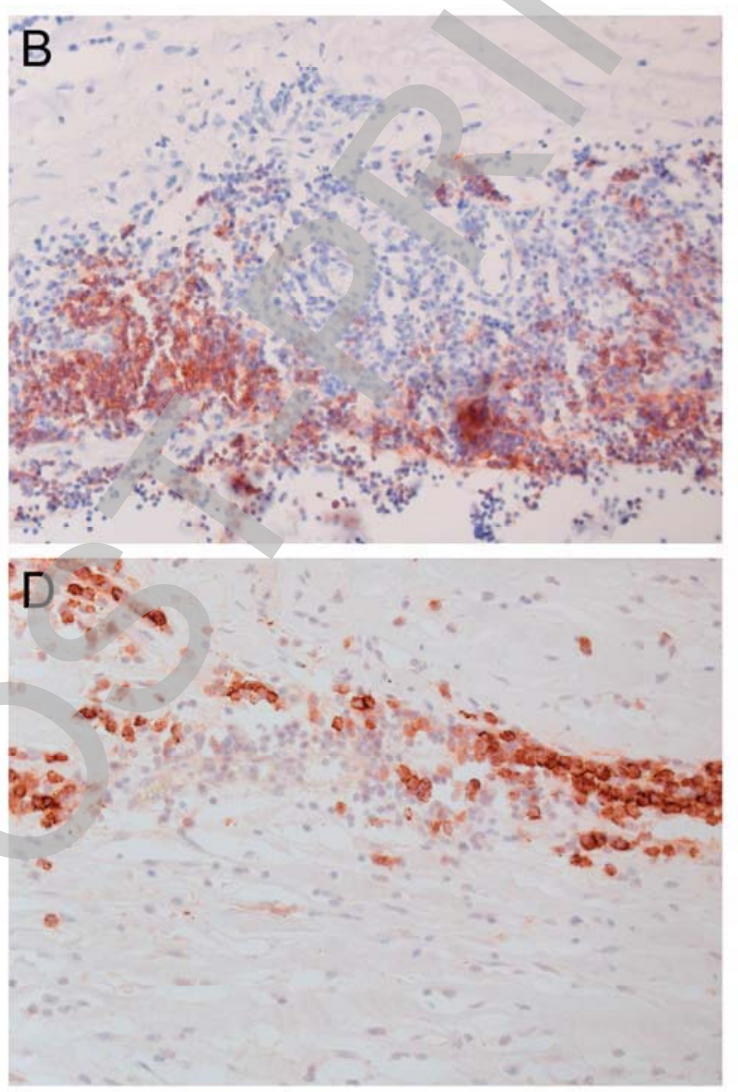

$\mathrm{F}$

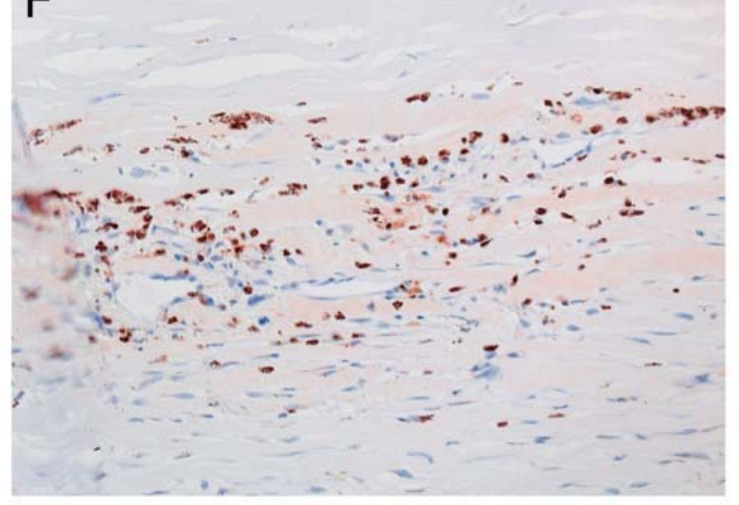




\section{Figure 2.}

A

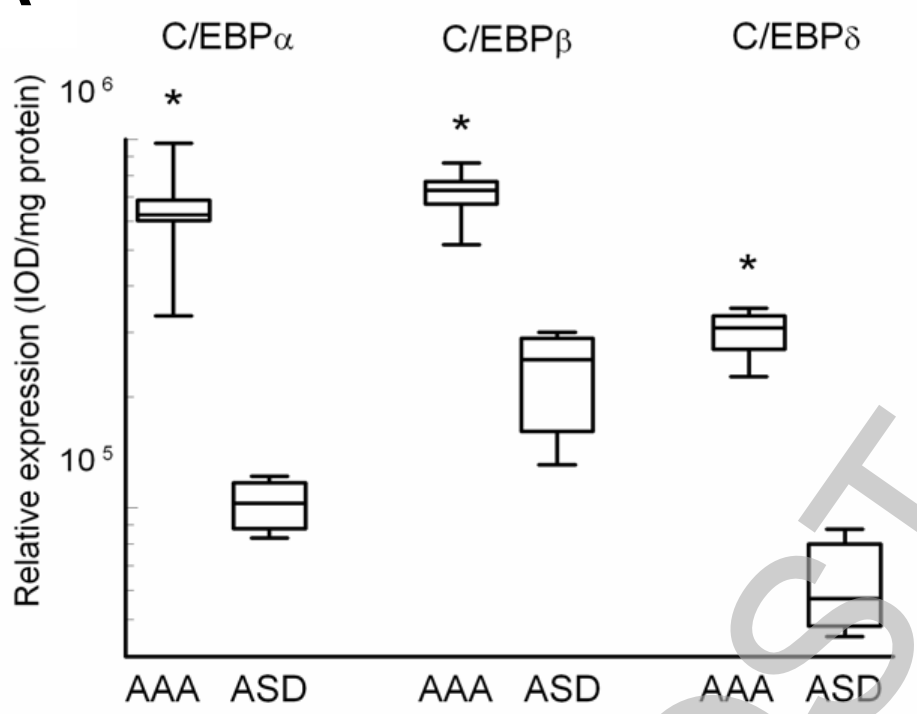

B

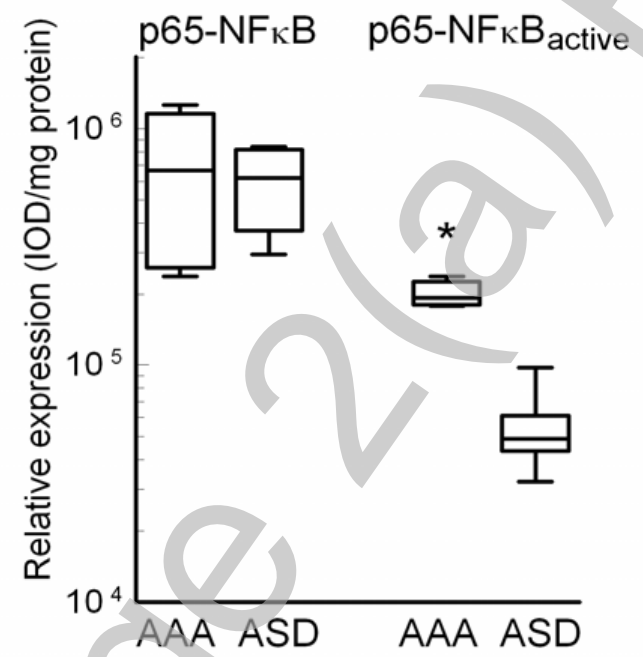


Lindeman et al.

\section{C}

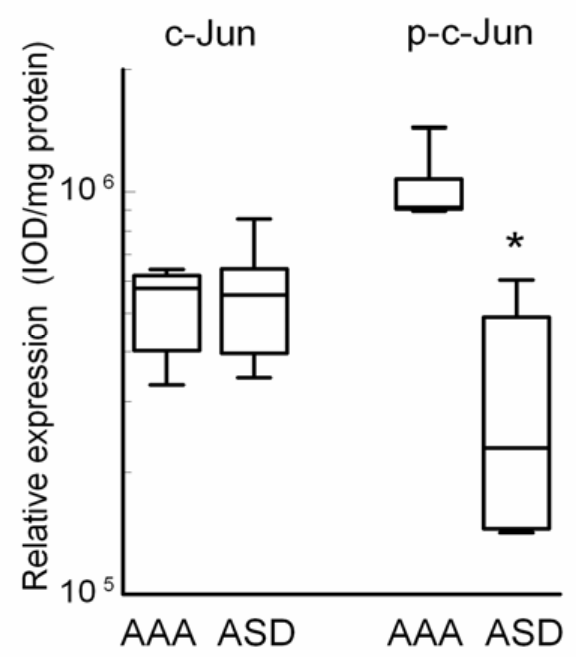


Lindeman et al.

Figure 3.

A

IL-6

IL-8
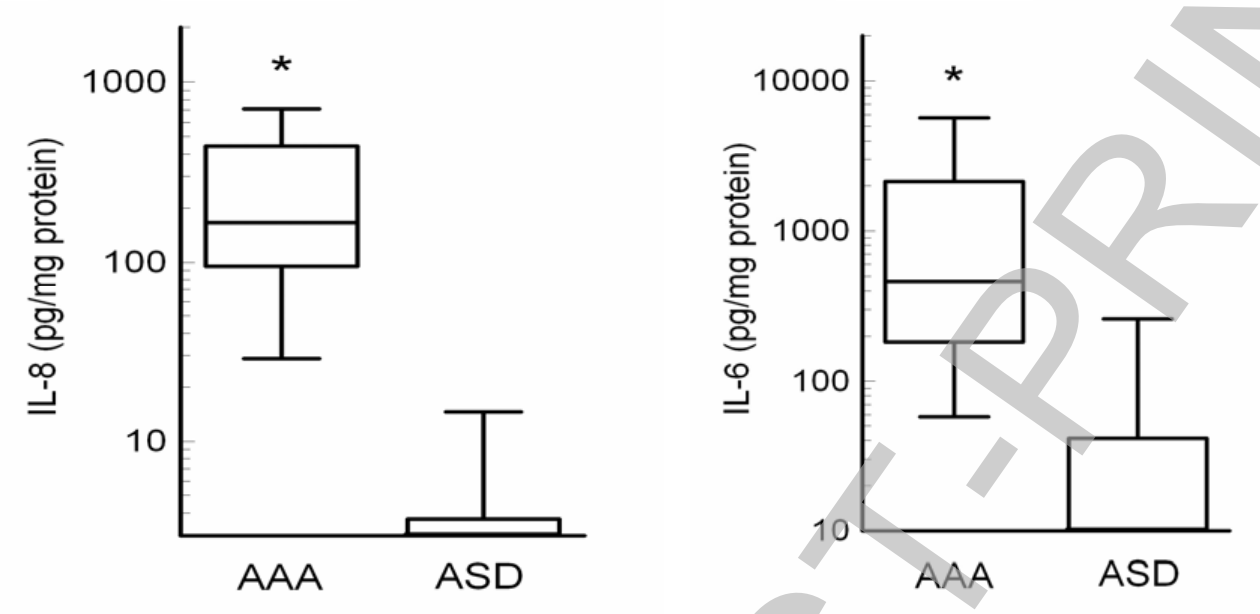

B

ASD

AAA 
Lindeman et al.

\section{Figure 4}

A

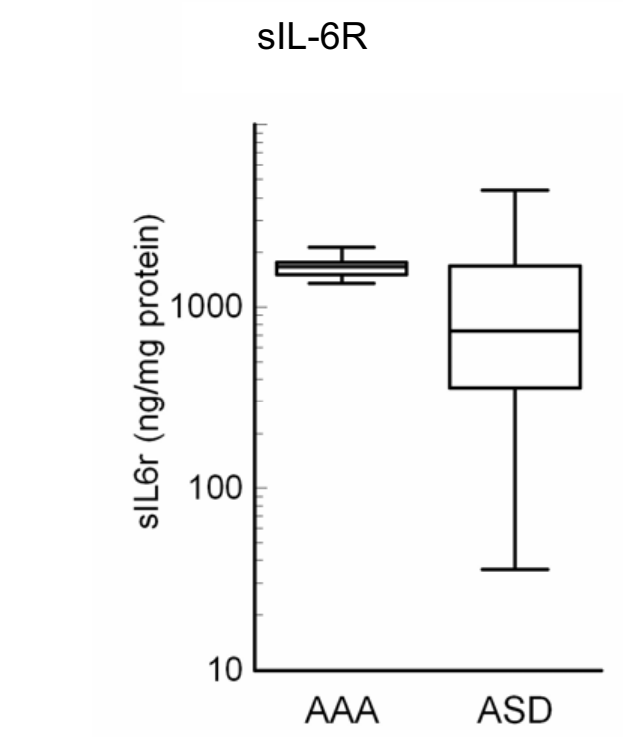

B

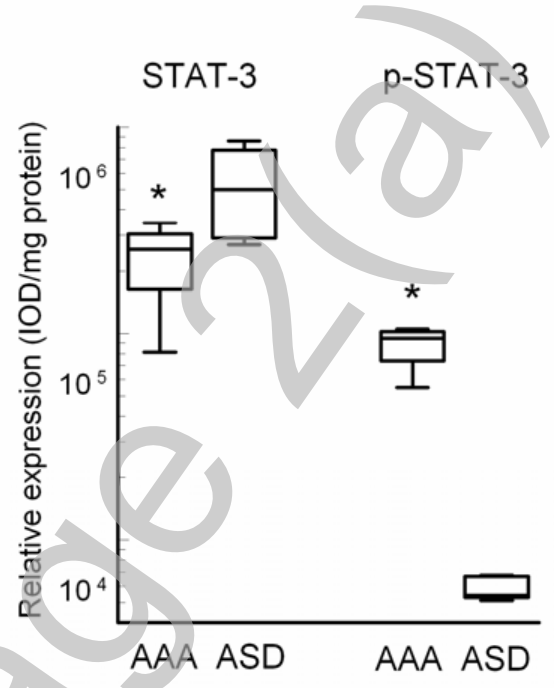


C

\section{Perforin}

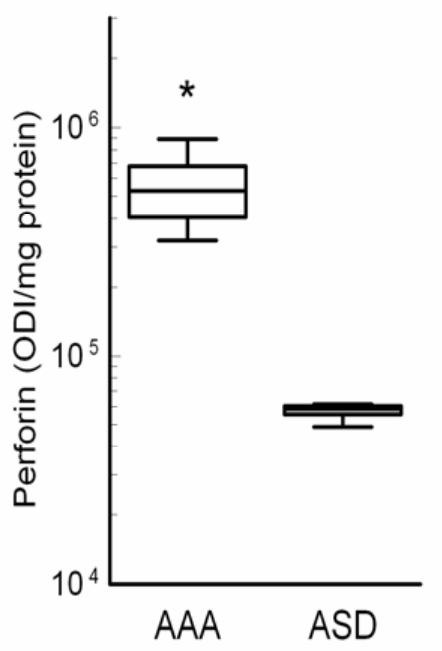

